\title{
Current Trends in Prevalence and Etiologic Factors Responsible for Hyponatremia in Hospitalized Patients
}

\section{Sandar Win ${ }^{1 *}$, Komal Patel ${ }^{1}$, Maria V DeVita ${ }^{1}$, Samuel J Wahl ${ }^{2}$ and Michael F Michelis ${ }^{1}$}

${ }^{1}$ Division of Nephrology, Department of Internal Medicine, Lenox Hill Hospital, Northwell Health, New York, USA

${ }^{2}$ Department of Pathology, Lenox Hill Hospital, Northwell Health, New York, USA

"Corresponding author: Sandar Win, Division of Nephrology, Department of Internal Medicine, Lenox Hill Hospital, Northwell Health, 100 E 77 th Street, New York, NY 10075, USA, Tel: 2019822604, 2013822604; E-mail: drsdarwin@gmail.com

Received date: December 9, 2016; Accepted date: December 21, 2016; Published date: December 26, 2016

Copyright: @ 2016 Win S, et al. This is an open-access article distributed under the terms of the Creative Commons Attribution License, which permits unrestricted use, distribution, and reproduction in any medium, provided the original author and source are credited.

\begin{abstract}
Purpose: Hyponatremia is the most common electrolyte disorder seen in hospitalized patients. The prevalence has been reported to be $5-30 \%$ depending on the clinical setting. The aim of this study was to determine the prevalence and etiologies of hyponatremia in patients now receiving care in our hospital.

Methods: We collected data on two separate days one month apart to evaluate the current prevalence and etiology of hyponatremia in patients in our hospital. We defined hyponatremia as a serum sodium level less than 135 $\mathrm{mEq} / \mathrm{L}$. We also divided hyponatremia patients into 2 groups depending on age to evaluate possible differences in etiology.

Results: We found that 41 out of 879 patients $(4.7 \%)$ were hyponatremic. Eighty-five percent of patient's exhibited a serum sodium of $130-134 \mathrm{mEq} / \mathrm{L}$. the majority of cases of hyponatremia were associated with medication use (34.1\%). Other associated etiologies were hypovolemia, malignancy, lung disorders, congestive heart failure $(\mathrm{CHF})$, patients on dialysis and postoperative patients. Twelve patients had data consistent with the syndrome of inappropriate secretion of antidiuretic hormone (SIADH). In terms of age, $56 \%$ of patients were more than 65 years of age. Patients receiving diuretics was a frequent etiology in older individuals, while dialysis therapy was common in younger patients.
\end{abstract}

Conclusion: Our findings suggest that the current prevalence of hyponatremia is not as high as reported in some previous studies. In addition, the hyponatremia observed tends to be mild and current related conditions include patients on dialysis therapy. Medication use continues to be a common responsible factor.

Keywords: Hyponatremia; Hyponatremia associated etiologies; Drug induced hyponatremia; Geriatric hyponatremia

\section{Introduction}

Hyponatremia is an important electrolyte disorder frequently encountered in hospitalized patients [1]. The prevalence of hyponatremia has been observed to be as high as $30 \%$ depending on the criteria for diagnosis, the clinical setting and the patient population [2-4]. Hyponatremia continues to be associated with significant morbidity and mortality especially when serum sodium levels are profoundly decreased or change rapidly [5-7], but the complications of hyponatremia may be avoidable when diagnosed early and appropriately treated [8].

The morbidity and mortality associated with hyponatremia also depends on the underlying disease states and associated medical conditions $[9,10]$. Clinical symptoms may vary from asymptomatic to seizures and coma $[11,12]$. We felt it is important to evaluate the current prevalence of this condition since there are many new drugs and clinical circumstances that may be associated with hyponatremia [13-15]. The aim of this study was to determine the prevalence and etiologies of hyponatremia in patients now receiving care in our hospital.

\section{Methods}

In order to determine the prevalence and etiology of hyponatremia in our hospital a search of laboratory data was performed to identify patients with this diagnosis on two separate days one month apart using a computerized data retrieval system. Our hospital is a 500 bed tertiary care center in a major metropolitan area. Patients from all medical and surgical services were included. Patients from the obstetrical, gynecological, and pediatric services were excluded. Two days data, one month apart to avoid patient duplication, were used to ensure adequate patient numbers. Hyponatremia was defined as a serum sodium of less than $135 \mathrm{mEq} / \mathrm{L}$. Hyponatremia was subdivided into 4 groups depending on serum sodium levels: $<120 \mathrm{mEq} / \mathrm{L}$ extreme, $120-124 \mathrm{mEq} / \mathrm{L}$ severe, $125-129 \mathrm{mEq} / \mathrm{L}$ moderate, and $130-134 \mathrm{mEq} / \mathrm{L}$ mild. A comprehensive chart review was then performed for patients found to be hyponatremic in order to identify diagnostic causes and associated conditions. We also evaluated characteristics of patients in age groups $<65$ years of age and $>65$ years of age. Finally, after determining the etiologies of hyponatremia in the patients identified, we compared these diagnoses to those found in prior studies. The laboratory data were obtained by standard measurements performed in the hospital Clinical Chemistry Department. For each etiology, the difference in prevalence between the two age groups was tested using the Chi-Square test or Fisher's 
Page 2 of 4

exact test, as deemed appropriate. A result was considered statistically significant at the $\mathrm{p}<0.05$ level of significance. All analyses were performed using SAS version 9.4 (SAS Institute, Cary, NC). The study protocol was approved by our Institutional IRB.

\section{Results}

There were a total of 879 patients with laboratory studies performed on the two separate days one month apart. Among them, 41 patients or $4.7 \%$ were found to be hyponatremic. We found that only $36.6 \%$ of patients had a normal serum sodium level on admission. Of interest, only $2.4 \%$ of patients had a serum sodium level $<120 \mathrm{mEq} / \mathrm{L}, 2.4 \%$ had a serum sodium 120-124 mEq/L and 9.8\% 125-129 mEq/L. Eighty-five percent of patients were found to have serum sodium $130-134 \mathrm{mEq} / \mathrm{L}$. Table 1 lists etiologies associated with hyponatremia. Patients, who evidenced multiple possible etiologic factors, which was not uncommon, were placed in the category where the most significant contributing cause was considered relevant. Important etiologic conditions were malignancy, noncancerous pulmonary disorders, diuretic use with or without heart failure, and other medications, but end stage renal disease was also noted in $9.8 \%$ of patients.

\begin{tabular}{|c|c|}
\hline Etiologies & Number of patients (\%) \\
\hline Diuretics w/wo CHF & $11(26.8)$ \\
\hline Hypovolemia (nondiuretic) & $12(29.3)$ \\
\hline SIADH & \multirow[t]{5}{*}{$12(29.3)$} \\
\hline $\begin{array}{l}\text { Pulmonary disease (not cancerous) } \\
n=5\end{array}$ & \\
\hline Malignancy $n=3$ & \\
\hline Idiopathic $n=1$ & \\
\hline SSRI $n=3$ & \\
\hline ESRD & $4(9.8)$ \\
\hline Postoperative & $2(4.9)$ \\
\hline
\end{tabular}

Table 1: Etiologies of hyponatremia (41 patients).

Medications (Table 2) were the most common etiologic factors associated with hyponatremia $(34.1 \%)$ with the majority of cases related to diuretic therapy which included standard agents such as furosemide and thiazides. SSRI use also was an important causal factor (3 patients). SIADH was felt to be present in 12 patients with malignancies, pulmonary disease, and patients receiving antidepressant therapy and uncertain etiology as associated conditions.

When patient age was considered, $56 \%$ of patients were greater than 65 years old. Associated causes such as hypovolemia and postoperative status did not reveal age differences. Diuretic use was seen more often in older patients while dialysis therapy was noted in younger patients (Table 3). These differences were not statistically significant, however.

\begin{tabular}{|l|l|l|}
\hline \multicolumn{2}{|c|}{ Diuretics 11 (26.8\%) } & Other drugs 3 (7.3\%) \\
\hline Diuretics alone 5 (12.2) & Diuretics + CHF 6 (14.6) & SSRI 3 (7.3) \\
\hline
\end{tabular}

Table 2: Drug therapies associated with hyponatremia $n=14$ (34.1\%).

\begin{tabular}{|l|l|l|l|l|}
\hline Etiology & $\begin{array}{l}\text { Overall } \\
\mathbf{n = 4 1 ( \% )}\end{array}$ & $\begin{array}{l}<\mathbf{6 5} \text { years } \\
\mathbf{n = 1 8}(\mathbf{4 4 \% )}\end{array}$ & $\begin{array}{l}\mathbf{> 6 5} \text { years } \\
\mathbf{n = 2 3}(\mathbf{5 6 \% )}\end{array}$ & $\mathbf{P = v a l u e}$ \\
\hline $\begin{array}{l}\text { Diuretics } \\
\text { Without CHF } \\
\text { With CHF }\end{array}$ & $11(26.8)$ & $4(22.2)$ & $7(30.4)$ & 0.29 \\
\cline { 2 - 5 } & $5(12.2)$ & $3(16.7)$ & $2(8.7)$ & 1.00 \\
\cline { 2 - 5 } & $6(14.6)$ & $1(5.6)$ & $5(21.7)$ & 0.21 \\
\hline $\begin{array}{l}\text { Hypovolemia } \\
\text { (nondiuretic) }\end{array}$ & $12(29.3)$ & $6(33.3)$ & $6(26.1)$ & 0.61 \\
\hline $\begin{array}{l}\text { ESRD on } \\
\text { Hemodialysis }\end{array}$ & $4(9.8)$ & $3(16.7)$ & $1(4.4)$ & 0.30 \\
\hline Postoperative & $2(4.9)$ & $1(5.6)$ & $1(4.4)$ & 1.00 \\
\hline SIADH & $12(29.3)$ & $6(33.3)$ & $6(26.1)$ & 0.61 \\
\hline
\end{tabular}

Table 3: Influence of age on etiologies of hyponatremia.

\section{Discussion}

Hyponatremia remains a common clinical disorder encountered in both hospitalized and nonhospitalized patients [16]. This study demonstrated a prevalence of $4.7 \%$ in hospitalized patients evaluated on 2 separate days one month apart. Of interest, $36.6 \%$ did not evidence hyponatremia on admission demonstrating that the majority of these cases acquired the abnormality prior to hospitalization. Attention to patients with decreased serum sodium levels remains relevant since data continues to accumulate confirming increased morbidity and mortality associated with this disorder [5-7,9]. Studies have demonstrated changes in mentation and mobility in hyponatremic patients [17] and changes in bone structure and susceptibility to fracture have also been reported $[18,19]$. Interest in hyponatremia has been further stimulated by the recent development of specific vasopressin receptor blocking agents which can facilitate an increase in serum sodium levels in patients with clinically significant low levels [20-23].

Our data revealed that the degree of hyponatremia was often mild. Eighty-five percent of patients exhibited a serum sodium of 130-134 $\mathrm{mEq} / \mathrm{L}$ and only $2.4 \%$ of patients were in the category of a serum sodium level less than $120 \mathrm{mEq} / \mathrm{L}$, demonstrating that the degree of decrease in serum sodium currently observed is often not profound. Studies have demonstrated that bone changes can occur even with mild hyponatremia, however $[18,24]$. It is noteworthy that almost $10 \%$ of patients demonstrated serum sodium values $125-129 \mathrm{mEq} / \mathrm{L}$, levels that require more active intervention. The data further revealed etiologies of hyponatremia similar to those recorded in earlier studies [25]. The majority of patients exhibited medication related hyponatremia $(34.1 \%)$ and it was discovered that hyponatremia was related to diuretic use in most of these patients (78.6\%) as has been described earlier [26]. SSRIs were also a common etiologic factor indicating the continued risks associated with the use of these agents $[13,14]$. Since hyponatremia can affect mentation it is important to rule out this diagnosis when patient's exhibit abnormalities of central nervous system function.

Other important causes of hyponatremia noted in our patients were malignancy, pulmonary disease, and heart failure. Twelve patients including three who were receiving antidepressant (SSRI) therapy, which can be associated with increased vasopressin activity, exhibited features consistent with a diagnosis of SIADH. Hypovolemia with a 
Page 3 of 4

positive response to volume replacement was also common (29.3\%). Patients with postoperative hyponatremia possibly related to excess vasopressin activity were also identified, and it was notable that dialysis dependent patients, who represented a new category, comprised an important group of our patient population (9.8\%). These patients had multiple etiologies for ESRD and the hyponatremia was felt to be largely dilutional. This association gains significance since hyponatremia in maintenance hemodialysis patients has now been recognized to be associated with increased mortality [26]. An early study by Waiker et al. [27] evaluating more than fifteen hundred patients revealed that lower predialysis serum sodium concentration increased the risk of all-cause mortality. A more recent study of more than 6000 hemodialysis patients by Nigwekar et al. [26] demonstrated that hyponatremia was associated with hypercalcemia and hypoparathyroidism and increased 1 year mortality. In that study, similar to our data, $89.2 \%$ of hyponatremic patients had sodium levels of $130-134 \mathrm{mEq} / \mathrm{L}$. The latter authors speculate that such electrolyte changes could relate to bone mineral abnormalities.

Statistical evaluation of diagnoses in relation to patients' age distribution was limited by small patient numbers. Numerically it appeared that the elderly, defined as $>65$ years of age, who comprised the majority of our patients, demonstrated diuretic therapy as a common etiologic factor, while younger patients exhibited end stage renal disease (ESRD) as an associated disorder related to the development of hyponatremia. The data suggest that hyponatremia secondary to traditionally recognized causes remains common in both age groups, but patients with ESRD now also contribute to the occurrence of this complication. The continued importance of diuretic therapy as an etiologic factor for hyponatremia suggests that frequent monitoring of laboratory data and instruction on fluid intake and medication use, particularly during episodes of gastrointestinal disease, might avoid this condition in patients treated with natriuretic agents. In addition, complications of the misdiagnosis of the etiology of hyponatremia, accompanied by the indiscriminate use of large volumes normal saline, may worsen serum sodium levels in patients with elevated vasopressin levels [8]. It should be emphasized, however, that patients may have multiple causes for a decrease in serum sodium. For example a patient with SIADH and nausea and vomiting may require volume replacement prior to instituting measures to create negative water balance.

Important observations produced by our data include the fact that hyponatremia seems to be not as frequent in hospitalized patients as has been reported in some earlier studies $[6,10]$. Further, when it does occur, the degree of decrease in serum sodium is often not substantial. Both these findings may be the result of the recognition of the value of more frequent laboratory monitoring of patients on diuretics or who are receiving drugs that act on the central nervous system. As noted earlier, however, studies have suggested the possibility of bone abnormalities, fracture risk and functional central nervous system changes even with mildly decreased levels of serum sodium $[17,19]$.

\section{Conflict of Interest}

Authors declare that the research was conducted in the absence of any commercial or financial relationships that could be construed as a potential conflict of interest.

\section{Ethical Approval}

The study was performed on blood samples available in the clinical laboratory obtained from patients as part of routine studies not ordered by the study physicians. The study protocol was approved by our Institutional IRB.

\section{References}

1. Adrogue HJ, Madias NE (2000) Hyponatremia. N Engl J Med 342: 1581-1589.

2. Clayton JA, Jeune IR, Hall IP (2006) Severe hyponatremia in medical inpatients: aeitiology, assess ment and outcomes. Q J Med 99:505-511.

3. DeVita MV, Gardenswartz MH, Koneckky A (1990) Incidence and etiology of hyponatremia in an intensive care unit. Clin Nephrol 34: 163-166.

4. Vitting KE, Gardenswartz MH, Zabetakis PM (1990) Frequency of hyponatremia and nonosmolar vasopressin release in the aquired immunodeficiency syndrome. JAMA 263: 973-978.

5. Chua M, Hoyle GE, Soiza RL (2006) Prognostic implications of hyponatremia in elderly hospitalized patients. Arch Gerontol Geriatr 45: 253-258.

6. Whelan B, Bennett K, O’riordan D (2009) Serum sodium as a risk factor for in- hospital mortality in acute unselected general medical patients. Q J Med 102: 175-182.

7. Wald R, Jaber BL, Price LL, Upadhyay A, Madias NE (2010) Impact of hospital associated hyponatremia in selected outcomes. Arch Intern Med 170: 294-302.

8. Adrogue HJ, Madias NE (2012) The challenge of hyponatremia. J Am Soc Nephrol 23: 1140-1148.

9. Waikar SS, Mount DB, Curhan GC (2009) Mortality after hospitalization with mild, moderate and severe hyponatremia. Am J of Med 122: 857-865.

10. Turgutalp K, Ozhan O, Gok Oguz E, Horoz M, Camsari A, et al. (2013) Clinical features, outcome and cost of hyponatremia-associated admission and hospitalization in elderly and very elderly patients: a single-center experience in Turkey. Int Urol Nephrol 45: 265-273.

11. Nigro N, Winzeler B, Suter-Widmer I, Schuetz P, Arici B, et al. (2015) Symptoms and characteristics of individuals with profound hyponatremia: a prospective multicenter observational study. J Am Geriatr Soc 63: 470-475.

12. Spasovaski G, Vanholder R, Allolio B (2014) Clinical practice guideline on diagnosis and treatment of hyponatremia. Nephrol Dial Transplant 2: i1-i39.

13. Fabian TJ, Amico JA, Kroboth PD, Mulsant BH, Corey SE, et al. (2004) Paroxetine-Induced hyponatremia in older adults. Arch Intern Med 164: 327-332.

14. Wilkinson TJ, Begg EJ, Winter AC (1999) Incidence and risk factors for hyponatremia following treatment with fluoxetine or paroxetine in elderly people. Br J Clin Pharmacol 47: 211-217.

15. Hoorn EJ, Zietse R (2010) Water balance disorders after neurosurgery: the triphasic response revisited. NDT Plus 3: 42-44.

16. Miller M (2006) Hyponatremia and arginine vasopressin dysregulation: mechanisms, clinical consequences, and management. J Am Geriatr Soc 54: 345-353.

17. Renneboog B, Musch W, Vandemergel X, Manto MU, Decaux G (2006) Mild chronic hyponatremia is associated with falls, unsteadiness, and attention deficits. Am J Med 119: 71.e1-71.e8.

18. Verbalis JG, Barsony J, Sugimura Y (2010) Hyponatremia-induced osteoporosis. J Bone Miner Res 25: 554-563.

19. Sandhu HS, Gilles E, DeVita MV, Panagopoulos G, Michelis MF (2009) Hyponatremia associated with large-bone fracture in elderly patients. Int Urol Nephrol 41: 733-737. 
Citation: Win S, Patel K, DeVita MV, Wahl SJ, Michelis MF (2016) Current Trends in Prevalence and Etiologic Factors Responsible for Hyponatremia in Hospitalized Patients. J Nephrol Ther 6: 279. doi:10.4172/2161-0959.1000279

Page 4 of 4

20. Schrier RW, Gross P, Gheorghiade M, Berl T, Verbalis JG, et al. (2006) Tolvaptan, a selective oral vasopressin V2-Receptor antagonist, for hyponatremia. $n$ engl j med 355: 2099-2112.

21. Metzger BL, DeVita MV, Michelis MF (2008) Obserations regarding the use of the aquatic agent conivaptan for the treatment of hyponatremia. Int Urol Nephrol 40: 725-730.

22. Velez JC, Dopson SJ, Sanders DS, Delay TA, Arthur JM (2010) Intravenous conivaptan for the treatment of hyponatremia caused by the syndrome of inappropriate secretion of antidiuretic hormone in hospitalized patients: a single centre experience. Nephrol Dial Transplant 25: 1524-1531.

23. Vaghasiya RP, DeVita MV, Michelis MF (2011) Serum and urine responses to the aquaretic agent tolvaptan in hospitalized hyponatremic patients. Int Urol Nephrol 44: 865-871.
24. Kinsella S, Moran S, Sullivan MO, Molloy MG, Eustace JA (2010) Hyponatremia independent of osteoporosis is associated with fracture occurrence. Clin J Am Soc Nephrol 5: 275-280.

25. Kengne FG, Andres C, Sattar L, Melot C, Decaux G (2008) Mild hyponatremia and risk of fracture in the ambulatory elderly. QJM 101: 583-588.

26. Nigwekar SU, Wenger J, Thadhani R, Bhan I (2013) Hyponatremia, mineral Metabolism and Mortality in incident maintenance hemodialysis patients: A Cohort Study. Am J Kidney Dis 62: 755-762.

27. Waikar SS, Gary CC, Brunelli SM (2010) Mortality associated with low serum sodium concentration in maintenance hemodialysis. Am J of Med 124: $77-84$. 